\title{
Analisis Unit Cost Pelayanan Unit Laboratorium Rumah Sakit Naili DBS Tahun 2017 dengan Metode Activity Based Costing $(A B C)$
}

\author{
Ressa Oashttamadea ${ }^{1}$, Menkher Manjas² ${ }^{2}$ Yurniwati $^{3}$
}

\begin{abstract}
Abstrak
Activity-Based Costing ( $A B C)$ merupakan metode akuntansi yang mengidentifikasi dan mengalokasikan biaya kepada aktivitas. Metode ABC dapat memberikan perhitungan biaya yang akurat sehingga meningkatkan efektivitas dan efisiensi finansial sebuah rumah sakit yang sesuai dengan tujuan strategik organisasi. Unit laboratorium merupakan salah satu unit dengan beban kerja terbanyak dan berperan besar dalam proses diagnosis penyakit. Tujuan penelitian ini adalah untuk mengetahui aspek manajemen mengenai penetapan tarif pelayanan laboratorium dan mengidentifikasi unit cost pelayanan laboratorium RS Naili DBS tahun 2017 dengan metode ABC. Penelitian ini dilakukan dengan desain mixed method tipe sequential explanatory, yaitu analisis kualitatif yang diikuti analisis kuantitatif. Hasil penelitian kualitatif menunjukkan bahwa RS Naili DBS menggunakan sistem akuntansi tradisional dalam menghitung unit cost pelayanan laboratorium, yang tidak mempunyai sistem kontrol terhadap pemakaian sumber daya. Hasil penelitian kuantitatif menunjukkan bahwa perhitungan unit cost pelayanan laboratorium dengan metode ABC pada pemeriksaan hematologi rutin dan waktu pembekuan \& pendarahan memberikan hasil yang lebih rendah dibandingkan tarif rumah sakit (Rp 45.389,- dan Rp 33.904,-), dan kebalikannya pada pemeriksaan gula darah random (Rp 33.904,-). Peneliti menyarankan agar RS Naili DBS melalukan evaluasi atas unit cost pelayanan laboratorium, sumber daya yang digunakan, serta mengedukasi staf mengenai metode ABC.
\end{abstract}

Kata kunci: unit cost, activity based costing, pemeriksaan laboratorium

\begin{abstract}
Activity-Based Costing $(A B C)$ is an accounting method that identifies and assigns costs to overhead activities. It provides more accurate information about cost so that the hospital can boost its financial efficiency and effectivity as stated in their strategic planning. Laboratory unit is one of the busiest units which has a big role for doctors in diagnostic procedure. The aim of this study was to elaborate the regulation and examine the unit cost of laboratory services in Naili DBS Hospital in 2017 using ABC method. This research was conducted by using mixed method design, sequential explanatory type, first by conducting the qualitative analysis then quantitative analysis. The qualitative study showed that Naili DBS Hospital was using traditional accounting system in determining their unit cost which had no control of the use of their resources. The quantitative study showed that unit cost of routine blood count and clotting \& bleeding time are overcosting (Rp 45.389,-- and Rp 33.904,-) and random blood sugar is undercosting (Rp 33.904,-). This study suggests Naili DBS Hospital to evaluate their laboratory services' unit cost, the use of their resources, and to hold a training about $A B C$ method.
\end{abstract}

Keywords: unit cost, activity based costing, laboratory services

Affiliasi penulis: 1. Prodi S2 Kesehatan Masyarakat Fakultas Kedokteran Universitas Andalas, 2. Bagian IImu Bedah Ortopedi, Fakultas Kedokteran Universitas Andalas, 3. Departemen Akuntansi, Fakultas Ekonomi Universitas Andalas

Korespondensi: Ressa Oashttamadea, email:

oashttamadea@yahoo.com, telp: 085263322936

\section{PENDAHULUAN}

Pimpinan rumah sakit harus mampu menyediakan pelayanan kesehatan yang dibutuhkan masyarakat dengan kualitas yang baik dan harga yang masuk akal, oleh karena itu dibutuhkan informasi mengenai biaya aktual dari pelayanan yang mereka sediakan. Rumah sakit menggunakan akuntansi biaya untuk memperkirakan biaya unit layanan yang disediakan. Informasi tersebut dapat membantu rumah sakit dalam merancang anggaran dan harga yang realistis, mengidentifikasi biaya yang tidak efisien dan memproyeksikan efeknya terhadap sumber daya yang dimiliki. ${ }^{1,2}$

Saat ini terdapat dua metode akuntansi biaya, yaitu metode tradisional dan metode activity based costing $(\mathrm{ABC})$. Kekurangan dari akuntansi biaya tradisional yaitu hanya membebankan biaya produksi ke produk, sedangkan biaya lain yang berkaitan dengan produk, seperti beban penelitian dan pengembangan, beban pemasaran, beban distribusi, dan beban layanan 
pelanggan tidak dibebankan ke harga pokok tersebut. Hal ini mengakibatkan tidak akuratnya tarif yang harus dibayar oleh pemakai jasa, dimana tarif bisa menjadi lebih murah (undercosting) atau lebih mahal (overcosting) dari beban biaya yang seharusnya dikonsumsi. Sedangkan perhitungan harga pokok produk berbasis aktivitas, atau activity-based costing $(A B C)$, mengalokasikan sumber biaya kepada objek biaya seperti produk, pelayanan, atau pelanggan berdasarkan aktivitas yang dilakukan. 1,3,4

Menurut UU No. 44 tahun 2009, rumah sakit adalah institusi pelayanan kesehatan yang menyelenggarakan pelayanan kesehatan perorangan secara paripurna. Salah satu unit yang mempunyai beban kerja yang banyak pada rumah sakit adalah laboratorium karena unit ini menyediakan pelayanan diagnostik dengan berbagai variasi pemeriksaan. Analisis biaya memainkan peranan penting dalam pembuatan keputusan, dan membantu unit laboratorium dalam menentukan biaya yang sesungguhnya. Dalam hal ini, activity-based costing (ABC) dapat menganalisis hubungan antara biaya dan aktivitas yang lebih tepat dibandingkan penghitungan biaya tradisional. 2,5,6

Beberapa uraian di atas menjadi latar belakang untuk melakukan penelitian di Rumah Sakit Naili DBS dengan judul 'Analisis Unit Cost Pelayanan di Unit Laboratorium RS Naili DBS Padang Tahun 2017 dengan Metode Activity Based Costing'.

\section{METODE}

Jenis penelitian ini adalah mixed method research (MMR) tipe sequential explanatory, yaitu melakukan pengumpulan dan analisis data kualitatif pada tahap pertama, dan diikuti dengan pengumpulan dan analisis data kuantitatif pada tahap kedua. Penelitian ini dilakukan pada bulan Maret sampai dengan Juni tahun 2018, dan lokasi penelitian di Unit Laboratorium RS Naili DBS.

Subjek dalam penelitian ini adalah direktur, wakil direktur bidang pelayanan medis, wakil direktur bidang umum dan keuangan, kepala bagian keuangan, dan kepala unit laboratorium. Objek dalam penelitian ini adalah semua data terkait biaya pelayanan 3 pemeriksaan terbanyak di Unit Laboratorium RS Naili DBS pada tahun 2017, yaitu pemeriksaan hematologi rutin, gula darah random, serta waktu pembekuan dan waktu pendarahan

Data primer didapatkan melalui wawancara dan observasi untuk mengumpulkan informasi mengenai kebijakan tarif pelayanan laboratorium yang berlaku, aktivitas yang terkait dengan pelayanan di laboratorium, dan SDM yang terlibat. Data sekunder didapatkan melalui telaah dokumen yang berhubungan dengan aktivitas di laboratorium, seperti laporan keuangan, laporan kunjungan pasien ke laboratorium, data sarana dan prasarana, rekapitulasi gaji, dan dokumen pendukung lainnya.

Dalam menganalisis data secara kualitatif, terdapat tiga aktivitas yang dilakukan, yaitu: (1) Data reduction (Reduksi data); (2) Data display (Penyajian data); (3) Conclusion drawing/ verification (Verifikasi data).

Langkah-langkah analisis data kuantitatif adalah sebagai berikut: (1) Mengidentifikasi dan menggolongkan semua biaya ke dalam aktivitas; (2) Mengklasifikasikan aktivitas biaya ke dalam berbagai level aktivitas yang terdiri dari aktivitas berlevel unit, batch, produk, dan fasilitas; (3) Mengidentifikasi cost driver, (4) Menentukan tarif per unit cost driver, (5) Melakukan penelusuran dan pembebanan biaya ke produk; (6) Menghitung tarif pelayanan laboratorium; (7) Membandingkan hasil tarif layanan laboratorium dengan menggunakan metode activity based costing dan metode tradisional.

\section{HASIL}

Hasil penelitian kualitatif menunjukkan bahwa RS Naili DBS belum memiliki kebijakan mengenai penghitungan unit cost pelayanan laboratorium. Unit cost yang berlaku saat ini merupakan hasil rapat manajemen yang dilakukan dengan menghitung biaya bahan medis habis pakai, biaya penyusutan fasilitas, jasa dokter, lalu hasil tersebut dibandingkan dengan tarif rumah sakit kompetitor. Selain itu, RS Naili DBS belum menyertakan biaya jasa medis analis, biaya administrasi, dan bahan habis pakai lainnya, seperti alat tulis kantor, ke dalam perhitungan unit cost. 
Tabel 1. Menentukan Cost Per Unit berdasarkan Metode ABC

\begin{tabular}{|c|c|c|c|c|c|c|}
\hline AKTIVITAS & DRIVER & & TOTAL & $\begin{array}{c}\text { COST } \\
\text { DRIVER }\end{array}$ & & $\begin{array}{l}\text { OST PER } \\
\text { UNIT }\end{array}$ \\
\hline \multicolumn{7}{|l|}{ Unit level activity cost } \\
\hline a. Biaya gaji analis labor & jml pemeriksaan & $\mathrm{Rp}$ & 89.948 .116 & 11179 & $\mathrm{Rp}$ & 8.046 \\
\hline 1. Hematologi rutin & jml pemeriksaan & & & 2587 & & \\
\hline 2. Gula darah random & jml pemeriksaan & & & 2238 & & \\
\hline 3. Waktu pemb \& pend & jml pemeriksaan & & & 1077 & & \\
\hline b. Biaya gaji spPK & jml pemeriksaan & $\mathrm{Rp}$ & 73.342 .851 & 11179 & $\mathrm{Rp}$ & 6.561 \\
\hline 1. Hematologi rutin & jml pemeriksaan & & & 2587 & & \\
\hline 2. Gula darah random & jml pemeriksaan & & & 2238 & & \\
\hline 3. Waktu pemb \& pend & jml pemeriksaan & & & 1077 & & \\
\hline c. Biaya listrik, air, dan telepon & luas lantai & $\mathrm{Rp}$ & 410.526 .317 & 1524 & $\mathrm{Rp}$ & 269.374 \\
\hline 1. Hematologi rutin & luas lantai & & & 3,8 & & \\
\hline 2. Gula darah random & luas lantai & & & 3,3 & & \\
\hline 3. Waktu pemb \& pend & luas lantai & & & 1,6 & & \\
\hline \multicolumn{7}{|l|}{ Batch related activity cost } \\
\hline a. Biaya administrasi & jml pemeriksaan & $\mathrm{Rp}$ & 22.358 .000 & 11179 & $\mathrm{Rp}$ & 2.000 \\
\hline 1. Hematologi rutin & jml pemeriksaan & & & 2587 & & \\
\hline 2. Gula darah random & jml pemeriksaan & & & 2238 & & \\
\hline 3. Waktu pemb \& pend & jml pemeriksaan & & & 1077 & & \\
\hline b. Biaya kebersihan dan keamanan & luas lantai & $\mathrm{Rp}$ & 444.921 .724 & 1524 & $\mathrm{Rp}$ & 91.943 \\
\hline 1. Hematologi rutin & luas lantai & & & 3,8 & & \\
\hline 2. Gula darah random & luas lantai & & & 3,3 & & \\
\hline 3. Waktu pemb \& pend & luas lantai & & & 1,6 & & \\
\hline c. Biaya bahan medis habis pakai & jml pemeriksaan & $\mathrm{Rp}$ & 83.504 .512 & 11179 & $\mathrm{Rp}$ & 7.470 \\
\hline 1. Hematologi rutin & jml pemeriksaan & & & 2587 & & \\
\hline 2. Gula darah random & jml pemeriksaan & & & 2238 & & \\
\hline 3. Waktu pemb \& pend & jml pemeriksaan & & & 1077 & & \\
\hline d. Biaya ATK & jml pemeriksaan & $\mathrm{Rp}$ & 3.730 .500 & 11179 & $\mathrm{Rp}$ & 334 \\
\hline 1. Hematologi rutin & jml pemeriksaan & & & 2587 & & \\
\hline 2. Gula darah random & jml pemeriksaan & & & 2238 & & \\
\hline 3. Waktu pemb \& pend & jml pemeriksaan & & & 1077 & & \\
\hline \multicolumn{7}{|l|}{ Facility sustaining activity cost } \\
\hline a. Biaya depresiasi gedung & luas lantai & $\mathrm{Rp}$ & 360.450 .000 & 1524 & $\mathrm{Rp}$ & 236.516 \\
\hline 1. Hematologi rutin & luas lantai & & & 3,8 & & \\
\hline 2. Gula darah random & luas lantai & & & 3,3 & & \\
\hline 3. Waktu pemb \& pend & luas lantai & & & 1,6 & & \\
\hline b. Biaya depresiasi fasilitas & jml pemeriksaan & $\mathrm{Rp}$ & 5.500 .000 & 11179 & $\mathrm{Rp}$ & 492 \\
\hline 1. Hematologi rutin & jml pemeriksaan & & & 2587 & & \\
\hline 2. Gula darah random & jml pemeriksaan & & & 2238 & & \\
\hline 3. Waktu pemb \& pend & jml pemeriksaan & & & 1077 & & \\
\hline
\end{tabular}


Tabel 2. Membebankan Biaya ke Produk untuk Pemeriksaan Hematologi Rutin

\begin{tabular}{|c|c|c|c|c|c|}
\hline AKTIVITAS & \multicolumn{2}{|c|}{ TARIF PER UNIT } & \multirow{2}{*}{$\frac{\text { DRIVER }}{2587}$} & \multirow{2}{*}{\multicolumn{2}{|c|}{$\begin{array}{ll} & \text { TOTAL (Rp) } \\
\mathrm{Rp} & 20.815 .438\end{array}$}} \\
\hline Biaya gaji analis labor & $\mathrm{Rp}$ & 8.046 & & & \\
\hline Biaya gaji DPJP & $\mathrm{Rp}$ & 6.561 & 2587 & $\mathrm{Rp}$ & 16.972 .713 \\
\hline Biaya listrik, air, dan telepon & $\mathrm{Rp}$ & 269.374 & 88,7 & $\mathrm{Rp}$ & 23.893 .494 \\
\hline Biaya administrasi & $\mathrm{Rp}$ & 2.000 & 2587 & $\mathrm{Rp}$ & 5.174 .000 \\
\hline Biaya kebersihan dan keamanan & $\mathrm{Rp}$ & 291.943 & 3,8 & $\mathrm{Rp}$ & 1.109 .385 \\
\hline Biaya bahan medis habis pakai & $\mathrm{Rp}$ & 7.470 & 2587 & $\mathrm{Rp}$ & 19.324 .284 \\
\hline Biaya ATK & $\mathrm{Rp}$ & 334 & 2587 & $\mathrm{Rp}$ & 863.298 \\
\hline Biaya depresiasi gedung & $\mathrm{Rp}$ & 236.516 & 3,8 & $\mathrm{Rp}$ & 898.760 \\
\hline Biaya depresiasi fasilitas & $\mathrm{Rp}$ & 492 & 2587 & $\mathrm{Rp}$ & 1.272 .788 \\
\hline \multicolumn{3}{|c|}{ Total biaya untuk pelayanan hematologi rutin } & & $\mathrm{Rp}$ & 90.324 .159 \\
\hline \multicolumn{3}{|c|}{ Jumlah pasien } & & & 2587 \\
\hline \multicolumn{3}{|c|}{ Unit cost per pasien } & & $\mathrm{Rp}$ & 34.915 \\
\hline \multicolumn{3}{|c|}{ Laba $(30 \%)$} & & $\mathrm{Rp}$ & 10.474 \\
\hline \multicolumn{3}{|c|}{ Jumlah tarif } & & $\mathrm{Rp}$ & 45.389 \\
\hline
\end{tabular}

Tabel 3. Membebankan Biaya ke Produk untuk Pemeriksaan Gula Darah Random

\begin{tabular}{|c|c|c|c|c|c|}
\hline AKTIVITAS & \multicolumn{2}{|c|}{ TARIF PER UNIT } & \multirow{2}{*}{$\frac{\text { DRIVER }}{2238}$} & \multirow{2}{*}{\multicolumn{2}{|c|}{$\begin{array}{ll} & \text { TOTAL (Rp) } \\
\mathrm{Rp} & 18.007 .325\end{array}$}} \\
\hline Biaya gaji analis labor & $\mathrm{Rp}$ & 8.046 & & & \\
\hline Biaya gaji DPJP & $\mathrm{Rp}$ & 6.561 & 2238 & $\mathrm{Rp}$ & 14.683 .004 \\
\hline Biaya listrik, air, dan telepon & $\mathrm{Rp}$ & 269.374 & 3,3 & $\mathrm{Rp}$ & 889.810 \\
\hline Biaya administrasi & $\mathrm{Rp}$ & 2.000 & 2238 & $\mathrm{Rp}$ & 4.476 .000 \\
\hline Biaya kebersihan dan keamanan & $\mathrm{Rp}$ & 291.943 & 3,3 & $\mathrm{Rp}$ & 964.361 \\
\hline Biaya bahan medis habis pakai & $\mathrm{Rp}$ & 7.470 & 2238 & $\mathrm{Rp}$ & 16.717 .336 \\
\hline Biaya ATK & $\mathrm{Rp}$ & 334 & 2238 & $\mathrm{Rp}$ & 746.834 \\
\hline Biaya depresiasi gedung & $\mathrm{Rp}$ & 236.516 & 3,3 & $\mathrm{Rp}$ & 781.270 \\
\hline Biaya depresiasi fasilitas & $\mathrm{Rp}$ & 492 & 2238 & $\mathrm{Rp}$ & 1.101 .082 \\
\hline \multicolumn{3}{|c|}{ Total biaya untuk pelayanan gula darah random } & & $\mathrm{Rp}$ & 58.367 .022 \\
\hline \multicolumn{3}{|c|}{ Jumlah pasien } & & & 2238 \\
\hline \multicolumn{3}{|c|}{ Unit cost per pasien } & & $\mathrm{Rp}$ & 26.080 \\
\hline \multicolumn{3}{|c|}{ Laba $(30 \%)$} & & $\mathrm{Rp}$ & 7.824 \\
\hline \multicolumn{3}{|c|}{ Jumlah tarif } & & $\mathrm{Rp}$ & 33.904 \\
\hline
\end{tabular}


Tabel 4. Membebankan Biaya ke Produk untuk Pemeriksaan Waktu Pembekuan dan Waktu Pendarahan

\begin{tabular}{|c|c|c|c|c|c|}
\hline AKTIVITAS & \multicolumn{2}{|c|}{ TARIF PER UNIT } & \multirow{2}{*}{$\begin{array}{r}\text { DRIVER } \\
1077\end{array}$} & \multirow{2}{*}{\multicolumn{2}{|c|}{$\begin{array}{r}\text { TOTAL (Rp) } \\
8.665 .723\end{array}$}} \\
\hline Biaya gaji analis labor & $\mathrm{Rp}$ & 8.046 & & & \\
\hline Biaya gaji DPJP & $\mathrm{Rp}$ & 6.561 & 1077 & $\mathrm{Rp}$ & 7.065 .950 \\
\hline Biaya listrik, air, dan telepon & $\mathrm{Rp}$ & 269.374 & 1,6 & $\mathrm{Rp}$ & 428.206 \\
\hline Biaya administrasi & $\mathrm{Rp}$ & 2.000 & 1077 & $\mathrm{Rp}$ & 2.154 .000 \\
\hline Biaya kebersihan dan keamanan & $\mathrm{Rp}$ & 291.943 & 1,6 & $\mathrm{Rp}$ & 464.083 \\
\hline Biaya bahan medis habis pakai & $\mathrm{Rp}$ & 7.470 & 1077 & $\mathrm{Rp}$ & 8.044 .938 \\
\hline Biaya ATK & $\mathrm{Rp}$ & 334 & 1077 & $\mathrm{Rp}$ & 359.401 \\
\hline Biaya depresiasi gedung & $\mathrm{Rp}$ & 236.516 & 1,6 & $\mathrm{Rp}$ & 375.973 \\
\hline Biaya depresiasi fasilitas & $\mathrm{Rp}$ & 492 & 1077 & $\mathrm{Rp}$ & 529.877 \\
\hline \multicolumn{4}{|c|}{ Total biaya untuk pelayanan waktu pembekuan \& pendarahan } & $\mathrm{Rp}$ & 28.088.151 \\
\hline \multicolumn{4}{|c|}{ Jumlah pasien } & & 1077 \\
\hline \multicolumn{4}{|c|}{ Unit cost per pasien } & $\mathrm{Rp}$ & 26.080 \\
\hline \multicolumn{4}{|c|}{ Laba $(30 \%)$} & $\mathrm{Rp}$ & 7.824 \\
\hline \multicolumn{4}{|c|}{ Jumlah tarif } & $\mathrm{Rp}$ & 33.904 \\
\hline
\end{tabular}

Dalam mengajukan permintaan alat, kepala unit mengajukan amprahan yang tertuju kepada direktur melalui wakil direktur dan kepala bagian keuangan. Sedangkan untuk penyediaan bahan habis pakai, kepala unit mengisi amprahan manual dan formulir di SIM RS lalu mengajukan ke bagian farmasi (untuk bahan medis) atau logistik (untuk bahan non medis seperti ATK). Walaupun telah mempunyai metode pengamprahan sarana dan prasarana, RS Naili DBS belum melakukan pengendalian yang terstruktur terhadap pemakaian sarana dan prasarana tersebut.

Permasalahan terkait unit cost pelayanan laboratorium yang dihadapi oleh RS Naili DBS adalah keuntungan ataupun kerugian masing-masing unit belum tergambar dengan jelas, terutama unit laboratorium. Untuk itu pihak manajemen RS Naili DBS mengharapkan di masa yang akan datang masingmasing unit mempunyai unit cost yang dihitung secara menyeluruh, yang dapat menggambarkan pendapatan RS secara akurat.

Berdasarkan pengolahan data dengan metode $A B C$, tarif untuk pemeriksaan hematologi rutin sebesar Rp 45.389,-, pemeriksaan gula darah random sebesar Rp 33.904,-, dan pemeriksaan waktu pembekuan dan waktu pendarahan sebesar Rp 33.904,-. Apabila dibandingkan dengan perhitungan metode tradisional, pada pemeriksaan hematologi rutin dan waktu pembekuan \& pendarahan, metode $A B C$ menghasilkan tarif yang lebih kecil, dengan selisih Rp 38.611,- dan Rp 8.096, sedangkan pada pemeriksaan gula darah random, metode $A B C$ memberikan hasil yang lebih besar dengan selisih Rp 12.904,-

\section{PEMBAHASAN}

Metode $A B C$ merupakan sebuah metode yang dikembangkan dengan kelebihan bahwa metode $A B C$ dapat mengidentifikasi biaya tidak langsung dari kegiatan manajemen. Strategi penetapan tarif sebuah perusahaan hendaknya menggunakan metode costplus, yaitu dengan menghitung unit cost dengan metode $A B C$ lalu menetapkan target keuntungan perusahaan. Unit cost yang tinggi dapat mengakibatkan tarif yang tinggi pula, namun berefek pada hilangnya sifat kompetitif pasar. ${ }^{7}$ Saat ini RS Naili DBS belum memiliki kebijakan mengenai prosedur penetapan unit cost laboratorium. Agar dapat meningkatkan daya saing di pasaran, RS Naili DBS perlu meninjau kembali tarif yang berlaku dengan melakukan identifikasi aktivitas serta alokasi biaya yang tepat yang dapat menghasilkan unit cost yang akurat.

RS Naili DBS telah mempunyai standar operasional prosedur (SOP) pengadaan bahan habis pakai beserta alur penggunaannya di unit laboratorium, namun belum memiliki SOP mengenai evaluasi pemakaian bahan habis pakai tersebut. Terkait dengan hal ini, proses bisnis merupakan sejumlah aktivitas 
yang mengubah input menjadi output. Proses bisnis berhubungan erat dengan unit cost dan dalam pengelolaannya perlu dilaksanakan perencanaan, pelaksanaan, pengawasan, dan penilaian. Proses produksi berpengaruh besar pada produk yang dihasilkan. Semua proses harus dilakukan secara benar, namun pada kenyataannya tidak semua proses dapat dilakukan sesuai dengan standar operasional prosedur (SOP) sehingga dapat menghambat jalannya perusahaan untuk mencapai target dan berisiko terhadap kerugian yang akan ditimbulkan bagi perusahaan. ${ }^{8,9}$ Berdasarkan hal tersebut, RS Naili DBS perlu menetapkan sebuah sistem pengawasan dan pelaporan penggunaan bahan habis pakai agar dapat melaksanakan evaluasi terhadap proses bisnis yang sedang berjalan di unit laboratorium, yang terkait dengan performance (biaya dan waktu), efficiency (efisiensi waktu, sumber daya, dan biaya), dan realibility (frekuensi kegagalan prosedur pemeriksaan) agar tidak terjadi kerugian di unit laboratorium.

Analisis biaya pemeriksaan hematologi rutin dengan metode $\mathrm{ABC}$ menghasilkan perhitungan yang lebih kecil dibandingkan tarif yang berlaku saat ini. Untuk melakukan pemeriksaan hematologi rutin, unit laboratorium menggunakan alat hematology analizer yang dalam satu kali penggunaan dapat menghasilkan parameter yang terkait dengan hematologi. Dalam hal ini seharusnya penghitungan unit cost dilakukan secara keseluruhan, namun rumah sakit menetapkan tarif sebesar Rp.21.000,- untuk setiap parameter yang diperiksa. Akibatnya, pemeriksaan hematologi rutin yang terdiri dari 4 parameter dikenakan tarif sebesar Rp.84.000,- atau setara dengan 4 kali pemeriksaan. Hal ini mengakibatkan terjadi overcosting pada tarif yang berlaku saat ini.

Pada pemeriksaan waktu pembekuan dan waktu pendarahan, analisis biaya dengan metode $A B C$ menghasilkan perhitungan yang lebih kecil. Hal yang sama juga terjadi seperti pemeriksaan hematoogi rutin, dimana dalam melakukan pemeriksaan waktu pembekuan \& pendarahan, analis labor hanya perlu melakukan pemeriksaan waktu pembekuan saja. Akibatnya, pemeriksaan waktu pendarahan \& pembekuan dikenakan tarif sebesar $\mathrm{Rp} 42.000$ yang setara dengan 2 kali pemeriksaan. Hal ini menunjukkan bahwa rumah sakit menentukan harga jual yang tinggi (overpricing).

Pada pemeriksaan gula darah random, analisis dengan metode $A B C$ menghasilkan perhitungan yang lebih besar dibandingkan dengan tarif yang berlaku saat ini. Hal ini menunjukkan bahwa rumah sakit menentukan harga jual yang rendah (underpricing). Perbedaan pada tarif tersebut dapat terjadi karena terdapat perbedaan dalam pembebanan biaya overhead pada masing-masing produk. Pada sistem biaya tradisional, pemakaian biaya overhead oleh produk diasumsikan untuk dijelaskan hanya dengan penggerak aktivitas berdasarkan unit, padahal dalam kenyataanya biaya tersebut merupakan biaya tingkat batch, tingkat produk dan tingkat fasilitas yang berubah sejalan dengan penggerak selain penggerak tingkat unit. Metode $\mathrm{ABC}$ memperbaiki keakuratan perhitungan biaya produk yang secara signifikan memperbaiki pengambilan keputusan. ${ }^{10}$

\section{SIMPULAN}

Manajemen RS Naili DBS belum memiliki kebijakan mengenai penghitungan unit cost rumah sakit, khususnya unit laboratorium. Tarif yang berlaku saat ini merupakan hasil rapat manajemen yang dihitung dengan metode tradisional. Berdasarkan metode $A B C$, besaran unit cost untuk pemeriksaan hematologi rutin sebesar $\operatorname{Rp} 45.389,-;$ pemeriksaan gula darah random sebesar Rp 33.904,-; dan waktu pembekuan \& pendarahan sebesar Rp 33.904,-. Hasil perhitungan tarif pelayanan laboratorium dengan menggunakan metode $A B C$ pada pemeriksaan hematologi rutin dan waktu pembekuan \& pendarahan menghasilkan tarif yang lebih kecil dibandingkan dengan tarif rumah sakit sedangkan pada pemeriksaan gula darah random, metode $\mathrm{ABC}$ memberikan hasil yang lebih besar dibandingkan tarif rumah sakit.

\section{DAFTAR PUSTAKA}

1. Javid, M., Hadian, M., Ghaderi, H., Ghaffari, S., dan Salehi, Masoud. Application of the ActivityBased Costing Method for Unit Cost Calculation in a Hospital. Global Journal of Health Science. 2016;8:164-172.

2. Gujral, S. Activity Based Costing Methodology as Tool for Costing in Hematopathology Laboratory. Indian J Pathol Microbiology. 2010;53:68-74. 
3. Riwayadi. Akuntansi Biaya: Pendekatan Tradisional dan Kontemporer. Jakarta: Salemba Empat; 2016.

4. Lestari, W., dan Permana, D. B. Akuntansi Biaya dalam Perspektif Manajerial. Depok: PT Raja Grafindo Persada; 2017.

5. Undang Undang Republik Indonesia No 44 Tahun 2009 tentang Rumah Sakit. Jakarta: Sekretariat Negara; 2009.

6. Mouseli, A., Barouni, M., Amiresmaili, M., Samice, S., dan Vali, L. Cost Price Estimation of Ckinical Laboratory Services Based on Activity Based Costing: A Case Study from A Developing Country. Electronic Physician. 2017;9:4077-4083.

7. Lu, T. Y. Competitive Price Strategy with Activity Based Costing. Procedia CIRP. 2017;63: 14-20.

8. Minartiningtyas, B. A. Analisa Proses Bisnis. 2018. (Diunduh 3 Juli 2018). Tersedia di https://kuliah.brigidaarie.com/wpcontent/uploads/2018/02/Sistem-Informasi-8.pdf

9. Sakti, L. C. Pemodelan dan Evaluasi Proses Bisnis Menggunakan Metode Quality Evaluation Framework (QEF). Jurnal Pengembangan Teknologi Informasi dan Komputer Vol 1. 2017; 1500-1507.

10. Yuliastanti, N. Penerapan Sistem Activity Based Costing (Studi Kasus pada Perusahaan Manufaktur Komponen Otomotif). Jakarta: Universitas Indonesia; 2010. 